\title{
O elo perdido da descentralização no Brasil: a promoção das capacidades estatais municipais pelo governo federal
}

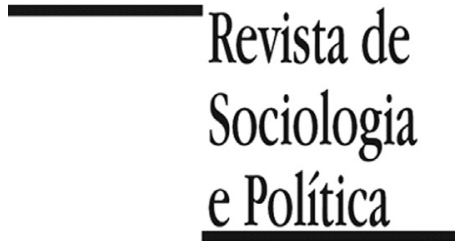

DOI $10.1590 / 1678-987321297702$

\author{
Eduardo José Grin'iD, \\ Fernando Luiz Abrucio' (iD \\ 'Departamento de Gestão Pública, Fundação Getúlio Vargas, São Paulo, SP, Brasil.
}

Palavras-chave: capacidades estatais; PMAT; dissonância federativa; municípios; cooperação intergovernamental.

RESUMO Introdução: o artigo aborda a promoção de capacidades estatais municipais por meio do Programa de Modernização das Administrações Tributárias (PMAT), implantado pelo BNDES entre 1997 e 2014. Busca-se analisar como programas federais que promovem capacidades estatais municipais, implantados por subgovernos (burocracias públicas federais com razoável autonomia de ação para definir suas regras), podem gerar dissonância federativa e reduzir sua possibilidade de acesso se desconsideram as distintas realidades municipais. Materiais e Métodos: utilizaram-se técnicas quantitativas (estatísticas descritivas geradas a partir dos relatórios de adesão municipal do PMAT e um Websurvey com as prefeituras) e qualitativas (entrevistas com gestores federais - BNDES, Ministério da Fazenda e Caixa Econômica Federal - e dirigentes políticos e técnicos da Confederação Nacional de Municípios, Associação Brasileira de Municípios e Frente Nacional de Prefeitos). O argumento teórico é que dissonâncias entre as agências federais provedoras de programas e os municípios como destinatários produzem baixo desempenho em termos de adesão. Resultados: a pesquisa mostrou como jogos da cooperação federativa podem resultar em visões contrastantes entre feds e locals. Empiricamente, essa discussão baseou-se na implementação do PMAT e como o mecanismo explicativo da dissonância federativa permite compreender a relação entre "doador" e "destinatário" no bojo das relações intergovernamentais. O resultado da cooperação federativa foi o oposto do que propugnava sua visão mais benigna, pois incentivou ações mais defensivas dos municípios que ponderaram custos e benefícios do acesso ao PMAT. Discussão: diante do desenho institucional do PMAT, considerando a combinação das exigências para o ingresso municipal e o fato de as candidaturas serem voluntárias, as induções favoreceram os maiores municípios. Gerou-se assimetria de acesso que favoreceu as cidades mais afluentes. A dissonância federativa entre o BNDES e os municípios é o que explica a realidade das adesões e o desencontro entre os feds e os locals. Com o seu formato, regras de indução e desacordos sobre seu funcionamento, em termos federativos, programas com estas características têm poucas chances de êxito como via de acesso para a grande maioria das cidades. O artigo contribui para o conhecimento sobre o desenho de programas federais e suas regras de acesso pelos entes subnacionais, sobretudo aqueles que visam promover capacidades estatais municipais. Outra contribuição é que a forma como feds concebem e implantam programas influencia o tipo de adesão municipal. A ação dos subgovernos pode gerar visões não coincidentes entre os gestores federais e a realidade municipal. Esse é outro aporte para a literatura de federalismo e capacidades estatais de governos locais.

Recebido em 18 de Janeiro de 2020. Aprovado em 14 de Setembro de 2020. Aceito em 1 de Janeiro de 2021.

\section{Introdução}

A pós 1988, os municípios brasileiros fortaleceram sua autonomia como ente federativo, mas, o desenvolvimento de capacidades estatais municipais segue sendo um elo escassamente considerado na trajetória recente do federalismo brasileiro (Grin \& Abrucio, 2018a). Essas carências debilitam a implementação de políticas públicas e a cooperação intergovernamental no bojo da descentralização, que foi o eixo organizador do federalismo após 1988. Cooperação federativa pode ser alcançada por diferentes arenas institucionalizadas para gerar interface entre as diferentes ordens de governo. Fóruns de cooperação territorial, por política pública ou programas federais são os caminhos mais usuais (Agranoff, 2001).

Este trabalho se circunscreve à última das três possibilidades e analisa, de 1999 a 2014, a implantação do Programa de Modernização das Administrações Tributárias (PMAT) criado pelo BNDES em 1997. Os resultados são analisados levando em conta se e quanto a adesão municipal foi afetada pelo seu formato 
institucional e regras de acesso. A escolha do PMAT e da adesão municipal ao programa como objeto do estudo justifica-se por ser o programa mais longevo, com mais recursos federais, dispor de dados longitudinais e possuir abrangência nacional. Este caso serve de subsídio para uma discussão mais ampla sobre cooperação intergovernamental para fomentar capacidades estatais municipais por meio de programas federais. Ademais, o artigo busca contribuir para a literatura sobre capacidades estatais municipais no Brasil, pois ainda há poucos trabalhos nesse campo (Marenco, 2017; Marenco, Blanco \& Joner, 2017; Grin \& Abrucio, 2018b; Grin et al, 2018).

$\mathrm{O}$ argumento teórico é que dissonâncias entre as agências federais provedoras de programas e os municípios como destinatários produzem baixo desempenho em termos de adesão (Downs, 1967; Pressman, 1975). A forma como feds concebem e implantam programas (Pressman, 1975) influencia a performance e o tipo de adesão municipal. A ação dos subgovernos (Wright, 1988), setores da burocracia pública que possuem autonomia para definir regras de acesso a programas, pode gerar jogos federativos pouco ajustados às diferentes realidades municipais. Empiricamente, será analisado como visões não coincidentes entre os gestores do PMAT e os municípios geraram efeitos na adesão dos governos locais ao programa.

Para realizar essa análise, o artigo está organizado como segue, além dessa introdução. A segunda seção, que revisa a literatura sobre cooperação intergovernamental por meio de programas federais, foi orientada exclusivamente para autores que tratam do problema da pesquisa e podem gerar insights relevantes que ajudem o pesquisador a se situar em relação ao campo de conhecimento (McMenamin, 2006). A terceira parte apresenta os procedimentos metodológicos da pesquisa. A quarta seção discute o desempenho do programa quanto às adesões municipais. A quinta parte aborda as dificuldades para que gestores federais e representantes do municipalismo alinhassem suas visões sobre o PMAT. A sexta seção contrasta visões dos gestores federais e dos governos municipais. A sétima seção apresenta os resultados de um survey com os municípios sobre o desenho do programa. Nas conclusões (seção VIII), coteja-se a discussão teórica com a análise do PMAT no tocante aos desafios da cooperação federativa em programas nacionais que visam modernizar a gestão municipal.

\section{A cooperação federativa: programas governamentais e capacidades estatais municipais}

Esta seção discute a literatura sobre cooperação federativa organizada por meio de programas formulados e implementados por agências nacionais, voltados à modernização da gestão municipal. Capacidades estatais são competências administrativas, burocráticas, técnicas e institucionais que permitem aos governos controlar recursos vitais para atenderem seus objetivos políticos e organizacionais (Veloso et al., 2011; Savoia \& Sen, 2015; Kim, McDonald \& Lee, 2018).

Regras de acesso a programas influenciam a adesão dos entes subnacionais, permitem compreender como são administrados e como afetam os resultados alcançados (Wright, 1988; Elazar, 1987). Em linha com os enfoques neo-institucionalistas, a melhor forma de analisar as ações do Estado consiste em identificar como regras inseridas nas políticas públicas influenciam a ação dos atores políticos (Skocpol, 2002). Por exemplo, a liberdade dos administradores que moldam as regras de programas pode gerar induções negativas que resultam na participação de municípios aquém da demanda potencial. Como o modelo institucional produz efeitos políticos, importa identificar quem conduz e qual é o lócus institucional (Wright \& Stenberg, 2007) dos programas, já que o seu desenho e suas regras não são neutros (Immergut, 1990). 
Por exemplo, a discricionariedade das agências federais quanto aos critérios para alocar recursos pode estimular escolhas pré-determinadas de políticas travestidas de requisitos técnicos. Nesse caso, os proponentes podem reter substancial influência sobre a cooperação intergovernamental e produzir distintos padrões de vínculos e impactos junto aos governos locais (Wright, 1988). Este comportamento decorre da ação subgovernos, que são órgãos cujos estilos e definições de políticas e relacionamento com outras instituições (Howlett \& Tosun, 2019; Biesbroek, Peters \& Tosun 2018) caracterizam-se por uma grande autonomia funcional para definir regras de implementação de políticas públicas.

Este aspecto é chave, pois entes federativos são autônomos para consentir ou não com as exigências dos programas federais. Portanto, importa conhecer as características dos participantes no sistema de ajuda federal e a difusão vertical de políticas precisa considerar estas condições para a sua implementação (Kim, McDonald \& Lee, 2018). Sem isso, é provável que cresçam as adesões das better-off cities em termos administrativos e políticos, pois as regras de acesso (Immergut, 1990) podem gerar uma equação inversa entre necessidades e capacidades locais: quem menos precisa, melhor se ajusta às condições de adesão (Wright, 1988; Terman et al., 2016).

Cidades menos necessitadas e mais afluentes podem ser as que mais aderem aos programas, pois possuem melhores condições de pagamento. $\mathrm{O}$ risco econômico (retenção de receitas financeiras) e político (prestar contas localmente) é comparativamente menor. Esta assimetria federativa pode ser mais pronunciada quando o acesso aos programas é voluntário e suas regras podem impactar desigualmente as possibilidades de participação (Pressman, 1975). Com efeito, trajetória de políticas e suas regras de funcionamento condicionam o comportamento dos atores políticos quanto às suas escolhas (Immergut, 1998).

A dinâmica intergovernamental pode influir de forma diferenciada sobre cada ente quanto aos benefícios de aderir às políticas federais, pois se algumas cidades participam desse jogo, muitas não o fazem diante das dificuldades identificadas nas regras de acesso. Nem todas as localidades poderão candidatar-se aos programas, ainda que as menores teriam mais interesse se exigências legais fossem acompanhadas por assistência técnica (Agranoff, 2007; Grodzins, 1984), pois "capacidade de absorção" é um obstáculo para receber apoio federal (Pressman, 1975).

Portanto, algumas cidades podem ganhar mais e outras podem obter menos do que precisam. Essa é a realidade de programas em que o acesso é voluntário e a avaliação de custos e benefícios não é clara para os solicitantes (Agranoff, 2001). Incentivos e recursos inseridos em políticas públicas moldam escolhas dos atores subnacionais em aderir ou não a elas (Pierson, 1993). Políticas públicas sinalizam para as esferas de governo o que pode ou não pode ser feito, bem como as recompensas e penalidades associadas a cada ação. Portanto, importa descobrir os mecanismos explicativos (fatores associados) que permitem compreender como ocorre a reprodução ou a mudança de padrões vigentes (Pierson, 2004).

Contudo, mesmo que o federalismo partilhe programas, suas regras podem incentivar "cartelização e monopólio de acesso" (Elazar, 1994). Governos com mais capacidades políticas e estatais costumam reforçar suas posições na arena federativa onde a politics se decide e as policies são formuladas. Localidades com melhores quadros profissionais e estrutura administrativa e orçamentária possuem mais recursos para cooperar com as agências federais (Grodzins, 1984), de forma que assimetrias de acesso podem realçar desigualdades federativas. 
Regras ou "amarras" (Pressman, 1975) costumam ser apropriadas distintamente pelos entes se requerem condições que são frágeis, inexistentes ou que não são vistas como estímulos à cooperação pelos municípios (Derthick, 1972). "Risco de não obediência" pode gerar perda de oportunidade e baixa eficácia na adesão pelos temores dos custos e penalidades associadas ao descumprimento de obrigações. Normas institucionalizadas em políticas públicas condicionam o processo decisório e fixam parâmetros para as opções dos atores políticos. Assim, governos locais apenas aparentemente realizam escolhas sobre os programas, pois suas regras são definidas nacionalmente (Wright, 1988; Skocpol, 2002). Ademais, quanto maior o rigor das normas, mais burocratizado costuma ser o acesso aos programas (Pressman, 1975).

Exigências podem gerar induções negativas que afastam entes interessados, razão pela qual calibrar prescrições e incentivos para o ingresso importa. Nesse processo, a adesão subnacional costuma seguir este roteiro: a) interesse diante da necessidade percebida $v$ s. disponibilidade de financiamento; b) capacidade administrativa para propor a candidatura e a probabilidade estimada de sucesso; c) agências federais avaliam as candidaturas visando medir necessidades, capacidade de implementação e benefícios (Wright, 1988). Porém, regras pouco amigáveis produzem "um cálculo ampliado" dos governos subnacionais quando comparam custos monetários, caso não cumpram as exigências, com os benefícios potenciais da adesão. As principais dificuldades para obter recursos financeiros dos programas provém da pouca clareza das regras, falta de prontidão das agências para explicá-las, documentação requerida, processo de aprovação e tempo de tramitação. Portanto, o trade-off entre vantagens e desvantagens é uma constante para os potenciais beneficiários (Pressman, 1975; Grodzins, 1984; Kane, 1984).

Se diretrizes são definidas por subgovernos pode-se gerar pouco alinhamento aos interesses locais e dificultar a cooperação federativa (Derthcik, 1972; Elazar, 1972, Agranoff \& Radin, 2014). "O escopo do plano e a ação de administradores nacionais em direção aos problemas afeta enormemente a atitude com a qual administradores [subnacionais] engajam-se em atividades de planejamento" (Grodzins, 1984, p. 66). Desse modo, o desejo "de governos capazes trabalhando juntos como um meio de manter a federação pode se deparar com a distância entre o formato de programas e a dificuldade de aderência pelos entes subnacionais" (Agranoff, 2001, p. 39).

Importa identificar quem decide e administra os regulamentos de acesso aos programas que definem seu escopo, rigidez/flexibilidade e condições da negociação intergovernamental, o que é essencial para analisar o intercâmbio federativo (Pressman, 1975). Nesse processo, o controle buscado pela esfera central e a intenção de autonomia local podem apresentar sinais trocados. Com efeito, instituições condicionam as opções dos atores políticos, pois constituem o contexto estratégico para a sua ação (Immergut, 1990).

Dissonâncias entre feds e locals podem impactar na adesão aos programas. Para os primeiros, municípios só veem sua própria realidade, o que justifica a formulação dos programas sem a sua participação. Entes locais demandam recursos, mas não exatamente os programas. São mais limitados para financiarem suas candidaturas em face de sua menor arrecadação tributária, o que os faz mais cautelosos orçamentariamente. São voltados a responsabilizarem as agências federais pela não adesão aos programas (Pressman, 1975; Downs, 1967; Brendan, 2014). Assim, os formuladores federais ampliam as exigências de acesso aos recursos porque desconfiam das intenções dos prefeitos em aplicá-los adequadamente (Wright, 1988).

Para os municípios, feds estão longe da sua realidade, o que gera falhas de concepção nos programas diante das heterogeneidades federativas (Derthcik, 
1972). Programas preocupam-se em gastar recursos; os municípios desejam economizá-los. Funcionários federais são ingênuos, pouco práticos e otimistas irrealistas sobre o alcance dos programas e as capacidades de implementação local. Imaginam "links", "coordenação" e "progresso" onde essas questões não existem. Para locals, mudanças nas regras dos programas produzem desconfiança e criam procedimentos burocráticos inflexíveis que dificultam sua execução (Pressman, 1975; Brendan, 2014; Wright, 1988).

O “doador” federal busca mover recursos, informação e assegurar controle das ações, visando mostrar o que deve ser realizado no nível local. Vale-se da estratégia da "demonstração", em que há um modelo de programa a ser implantado, ainda que os benefícios sejam tangíveis a poucos governos (Derthcik, 1972). Já os "destinatários" buscam atrair verbas e desejam autonomia para executarem os objetivos definidos pelo doador (Philipmore, 2013). A relação é potencialmente conflitiva, pois fundos federais definem regras sobre como gastar recursos, o que demanda que as cidades aceitem perder alguma autoridade decisória e autonomia (Pressman, 1975).

Essa relação pode criar um afastamento político dado o "efeito das imagens contrastantes" e constrangimentos estruturais (Pressman, 1975; Downs, 1967) que limitam a capacidade de os governos alcançarem seus objetivos de forma cooperativa. Governos diferem sobre políticas de financiamento se regras de acesso e forma de implementação tornam-se objeto de controvérsia. Nesse processo, pode ocorrer uma situação paradoxal na qual pequenos municípios, e que mais necessitam de apoio, sejam os que mais receiam ficar dependentes do governo federal. Assim, incentivos inseridos nas regras de políticas públicas moldam as escolhas dos atores políticos em aderir ou não a uma política pública (Pierson, 1993), sobretudo quando governos possuem autonomia para avaliar custos e benefícios.

Diferentes perspectivas no jogo intergovernamental podem tornar os entes mutuamente pouco simpáticos aos objetivos do outro, o que pode gerar ineficiência na implementação de programas (Wright, 1988). Por exemplo, o temor de custos antecipados e responsabilidades requeridas podem influir na decisão quanto à adesão (Agranoff \& McGuire, 2004). Se tais fatores são objeto de obrigações contratuais, talvez a busca de apoio federal seja secundarizada, mesmo que a necessidade persista. Este pode ser um jogo de cooperação ou conflito, a depender dos "mandatos" ou "imperativos funcionais" dos programas (Agranoff, 2001) junto aos municípios.

Nesse sentido, o argumento deste trabalho é que programas federais concebidos e implantados por subgovernos, cujas regras não os tornam acessíveis para todas localidades, geram dissonâncias federativas que influenciam os resultados em termos do número e perfil de adesão municipal. Empiricamente esse argumento será discutido tomando a implantação do PMAT pelo BNDES entre 1999 e 2014, e a adesão municipal como objeto de análise.

\section{Procedimentos metodológicos}

Esta pesquisa analisa o PMAT e sua performance quanto à adesão municipal entre 1999 e 2014. Não são avaliados os fatores ou condições pelas quais as capacidades estatais municipais são afetadas e porque existe variação local quanto à gestão de políticas. $\mathrm{O}$ caminho metodológico adotado consiste em analisar como o PMAT e seu desenho institucional operaram como variável independente para avaliar a adesão municipal como variável dependente. A discussão do caso busca mostrar como e por que as regras e a forma de implementação do programa geraram resultados em termos de acesso e adesão municipal que favoreceram as maiores cidades. 
Assume-se como premissa da pesquisa que porte populacional é uma variável diretamente associada com as características das capacidades estatais municipais, em linha com a literatura que empiricamente tem evidenciado essa conexão com a qualidade da burocracia municipal (Marenco, 2017; Marenco, Blanco \& Joner, 2017) ou na gestão financeira (Grin \& Abrucio, 2018b; Grin et $a 1,2018$ ). Ademais, cortes populacionais foram critérios-chave adotados pelo BNDES para a seleção de candidaturas municipais para o PMAT.

Estudos de caso partem de uma configuração empírica de condições contextuais para "explicar resultados históricos específicos, o conjunto de resultados comparáveis ou os processos escolhidos a serem estudados por causa de seu significado para os arranjos institucionais ou para a vida social em geral" (Ragin, 1987, p. 3). Busca-se encontrar as circunstâncias que inserem a análise numa moldura teórica e empírica que permita compreender as razões de sua configuração e, dessa forma, propor questões que sirvam para embasar novos estudos, como é o objetivo desse artigo. O PMAT, portanto, é um objeto de análise que ilustra um fenômeno mais amplo em termos teóricos e empíricos: de que forma programas federais voltados para promover capacidades estatais podem influenciar o comportamento dos municípios como público-alvo?

Analiticamente, esse processo se apoia em mecanismos explicativos (Mahoney, 2003) que buscam tornar inteligível as regularidades observadas nos fenômenos analisados, à luz das hipóteses de pesquisa. Nesse artigo, o mecanismo explicativo que fundamenta a análise do PMAT é a "dissonância federativa", derivada das visões que opõe feds e locals (Downs, 1967; Conlan \& Posner, 2016) e que decorre da forma como o BNDES formulou e implantou o PMAT. Este mecanismo permite compreender a característica das adesões municipais, as visões contrastantes entre os subgovernos federais e os governos locais e as opiniões das localidades sobre o programa. Este é o mecanismo utilizado para explicar a performance do PMAT quanto à adesão de municípios que buscaram modernizar suas capacidades de gestão.

A pesquisa utilizou duas técnicas quantitativas. Foram geradas estatísticas descritivas básicas relacionadas ao número de contratos do PMAT por estado, município e porcentual de financiamento obtido. Estes dados foram coletados junto a relatórios técnicos do programa no BNDES e por meio da Lei de Acesso a Informação. Estas informações foram cotejadas com seus portes populacionais, considerando o ano da contratação do programa, derivados da contagem populacional que o IBGE envia anualmente para o Tribunal de Contas da União. Este levantamento é fundamental para analisar a distribuição dos municípios que contrataram o programa com seu perfil demográfico e valores de empréstimo obtidos.

O segundo instrumento foi a aplicação de um Websurvey (Newcomer \& Triplet, 2006) enviado para os dirigentes municipais das secretarias de Finanças e/ou Administração dos 5570 municípios brasileiros com o suporte do software Survey Monkey. Aplicou-se a pesquisa entre outubro e dezembro de 2015 e 328 municípios a responderam (estes não coincidem com os 338 que contrataram o programa, pois este foi o número de localidades que participaram da pesquisa). Pelo Censo de 2010, 89\% dos municípios têm até 50 mil habitantes (linha de corte do PMAT Especial) e na pesquisa esses são 86,7\%, o que faz a amostra ser aderente ao perfil majoritário das localidades. Por fim, como o foco do survey foi identificar se o desenho do PMAT influenciou a contratação pelos municípios em uma amostra probabilística aleatória não é necessário identificar a relação entre respondentes e aderentes.

Essa estratégia se baseia em Luna e Soifer (2017) que utilizaram esse expediente para mensurar capacidades estatais subnacionais em países latino-americanos. O levantamento foi apoiado pela Associação Brasileira de 
${ }^{1}$ Sendo uma amostra probabilística aleatória, isso significa que a cada 100 questionários aplicados, em $90 \%$ deles a probabilidade de os resultados se repetirem variando $10 \%$ para menos ou $10 \%$ para mais.
Municípios/ABM, Confederação Nacional de Municípios/CNM e Frente Nacional de Prefeitos/FNP. Todas as etapas da pesquisa (avaliação do questionário, realização do pré-teste, carta de apresentação e o acesso aos municípios pelo mailing list que remeteu um link para o formulário ser acessado pela internet) foram apoiadas pelas três entidades.

O questionário buscou identificar o perfil da cidade, o conhecimento local do programa, se a localidade já havia acessado o programa e para que fim, se já havia submetido uma proposta para obter financiamento (que problemas ocorreram e se recebeu suporte técnico externo). Para quem contratou o programa, em qual modalidade do programa, objetivos e em que anos e quais resultados foram alcançados. O software gerou uma planilha Excel com as respostas que subsidiaram a construção das tabelas com os dados.

Nem todas as questões foram completadas por todos os respondentes, conforme indicado nas tabelas abaixo com os respectivos quantitativos de respostas, razão pela qual o $\mathrm{N}$ descrito nas notas de cada uma delas não é o mesmo, assim como as margens de erro e nível de confiança ${ }^{1}$. Excluíram-se todas as respostas com margem de erro superior a 10\% e menos de $90 \%$ de nível de confiança, o que só permitiu a utilização da informação coletada em quatro questões. Considerando esses procedimentos adotados para lidar com a aplicação do survey, e dada a natureza probabilística aleatória simples da pesquisa, reduzem-se eventuais vieses quanto aos dados coletados junto aos municípios.

Também foram realizadas seis entrevistas semiestruturadas: três com dirigentes e gestores responsáveis pelo PMAT no Ministério da Fazenda e Caixa Econômica Federal (Brasília) e BNDES (Rio de Janeiro) e três com dirigentes da ABM, CNM e FNP (Brasília), visando a conhecer as opiniões sobre o desenho, objetivos e forma de implementação do programa. As entrevistas tiveram duração média de 90 minutos e foram realizadas de forma presencial sendo gravadas e posteriormente transcritas. As entrevistas tiveram como principal objetivo avaliar o efeito das imagens contrastantes e o mecanismo da dissonância federativa entre feds e locals e por isso foram utilizadas em uma seção separada. Por fim, a pesquisa documental em publicações do BNDES e informações dos contratos obtidos por meio da Lei de Acesso à Informação serviu de base para a descrição do programa, seu histórico e modalidades.

\section{O PMAT: estrutura e finalidades}

O PMAT foi criado pelo BNDES, em 1997, e seu surgimento associou-se ao Programa de Estabilização Fiscal implementado em 1998 que buscava obter equilíbrio macroeconômico das contas públicas nacionais. Para tanto, promover a modernização da gestão fiscal, tributária e administrativa municipal era uma ação que o BNDES julgava estratégica para gerar qualidade dos serviços públicos e uma cidade melhor (Guarneri, 2002). Em 1999, o PMAT ampliou suas ações para educação, saúde e assistência social e passou a chamar-se Programa de Modernização da Administração Tributária e da Gestão dos Setores Sociais Básicos (BNDES, 2009).

Como o BNDES não possui capilaridade territorial, o Banco do Brasil foi sua porta de entrada desde o ano 2000, sobretudo para os pequenos municípios e projetos abaixo de R 6 milhões (valores de 2012). Em 2008, foi criado o PMAT Especial para cidades com até 50 mil habitantes, que se somou ao PMAT Tradicional. A Tabela 1 mostra estas duas modalidades do programa com suas regras básicas de prazo, valores financiáveis, participação do BNDES, escopo e perfil de município que podia candidatar-se.

Em 2010, três novas modalidades substituíram as anteriores: a) PMAT Automático (projetos até $\mathrm{R} \$ 10$ milhões para cidades com até 150 mil habitan- 
Tabela 1 - Principais condições PMAT Tradicional e PMAT Especial

\begin{tabular}{lcc}
\hline & PMAT Tradicional & PMAT Especial \\
\hline Prazo de carência & 2 anos & 2 anos \\
Prazo de amortização & 6 anos & 2 anos \\
Prazo Total & 8 anos & 4 anos \\
Apresentação do projeto & Normal & Simplificada \\
Valor máximo financiável & R\$ 60 milhões & R \$ 720 mil \\
Participação máxima & Até $90 \%$ ou 100\% & $100 \%$ \\
Escopo & Abrangente & Definido (cinco focos) \\
População do município & Sem limites & Até 50 mil habitantes \\
\hline
\end{tabular}

Fonte: Guia PMAT (2009).

tes e operado por agentes financeiros); b) PMAT Finem: cidades acima de 150 mil habitantes e financiamento até R $\$ 1$ milhão ou aquelas com até 150 mil habitantes e financiamento de mais de $\mathrm{R} \$ 10$ milhões operadas por agentes financeiros; b) operações diretas com o BNDES acima de R 10 milhões.

Visando atender a diversidade de municípios em termos de porte, o PMAT Automático alterou a forma de financiamento (valores $\mathrm{R} \$ 36,00$ per capita com teto de $\mathrm{R} \$ 60$ milhões para limites populacionais). Avaliou-se que esse formato agilizaria a contratação ao simplificar, padronizar e limitar o financiamento a um rol de pré-definido de ações. Julgava-se que as operações seriam facilitadas pela proximidade entre a instituição financeira responsável e o município. Em 2013, uma última mudança na formatação do programa criou as operações indiretas automáticas (financiamentos abaixo de R \$ 20 milhões com o suporte do agente financeiro) e operações diretas (financiamentos acima de $\mathrm{R}$ \$ 20 milhões com a intervenção do BNDES). Foi retirado o limite de $150 \mathrm{mil}$ habitantes para o PMAT Automático.

Embora o PMAT buscasse promover as capacidades dos governos municipais (Guarneri, 2002), seu foco sempre foi a administração tributária, pois o aumento da receita própria foi assumido como o marco zero da modernização gerencial. Municípios mais eficazes na cobrança de impostos, redução do seu déficit e ampliação de receitas próprias melhorariam sua inserção federativa. Os municípios não podiam mais se financiar apenas com as receitas dos impostos federais, e menos ainda por endividamentos impedidos pela Lei de Responsabilidade Fiscal (Afonso \& Araújo, 2001).

O objetivo era ampliar a autonomia política local restringida pela baixa capacidade tributária própria (Souza \& Blumm, 1999). Sendo os municípios o lugar dos cidadãos, qualificar sua autonomia administrativa e financeira era considerada uma condição necessária para promover bem-estar. Nesse sentido, o BNDES considerava-se uma instituição chave para reformular a gestão pública local e o PMAT era uma política pública para incrementar as capacidades de governo (Guarneri, 2002; BNDES, 2009). Aumentar receitas próprias (arrecadar mais), otimizar a aplicação de recursos (gastar bem) e reduzir custos (economicidade) (BNDES, 2011) eram vitais para um planejamento mais organizado do gasto público e uma gestão municipal mais eficiente.

\section{O desenho institucional do PMAT e seus efeitos no acesso pelos municípios}

Esta seção discute a performance do PMAT, considerando o número de contratos e sua distribuição por porte de município e por região. Busca-se uma 
primeira aproximação entre os resultados da cooperação federativa e a desigualdade de acesso municipal.

De 1998 a 2014 foram contratadas 366 operações em 338 municípios (alguns tiveram mais de um projeto), o que representa 6,07\% dos 5570 municípios. Informações detalhadas sobre o perfil populacional municipal e os porcentuais obtidos de financiamento/total financiado em pelo BNDES em cada estado da federação estão nas Tabelas 2A, 2B, 2C, 2D, 2E. Os dados estão apresentados com esses três parâmetros para possibilitar a identificação de três níveis de assimetria que se mesclam: acesso desigual por tamanho de município, por estado e região do país e do montante de financiamento obtido.

A distribuição dos contratos mostra que a região Sudeste reteve $45,6 \%$ (Tabela 2A) e o Sul 32,3\% (Tabela 2B) ambas com 77,9\% do total. O Nordeste recebeu 2,3\% dos financiamentos (Tabela 2C), o Centro-Oeste 6,51\% (Tabela 2D) e o Norte 3,25\% (Tabela 2E). Até 2013, a assimetria de acesso (Pressman, 1975) em favor do Sul e Sudeste, que em termos relativos possuem municípios com um nível maior de capacidade estatal, foi muito significativa.

Considerando o porte e a concentração regional dos municípios que contrataram, Belo Horizonte, Rio de Janeiro e São Paulo responderam por 28,3\% do total investido e 17 capitais - 5\% das 338 cidades - captaram 39,7\% do montante global. Esta apropriação desigual está em linha com Wright (1988): as "melhores" cidades aderiram por dominarem mais capacidades administrativas e políticas. Se não houve uma "cartelização e monopólio de acesso" (Elazar 1994), na prática, a seleção favoreceu as cidades mais capacitadas. Uma das

Tabela 2A - Contratos por região, porte populacional e porcentual de financiamento do BNDES (Sudeste)

\begin{tabular}{|c|c|c|}
\hline Estado (cidades) & Porte populacional (mil/habitantes) & Percentual financiado \\
\hline \multirow[t]{6}{*}{ Minas Gerais (capital + 26 cidades) } & Até 20: quatro cidades & 0,09 \\
\hline & 20 a 50: três cidades & 0,17 \\
\hline & 50 a 100: 12 cidades & 1,06 \\
\hline & 100 a 500: seis cidades & 2,22 \\
\hline & + de 500: uma cidade + Belo Horizonte & 11,3 \\
\hline & Total & 14,8 \\
\hline \multirow[t]{5}{*}{ Rio de Janeiro (capital + 11 cidades) } & De 20 a 50: duas cidades & 0,09 \\
\hline & De 50 a 100: uma cidade & 0,09 \\
\hline & 100 a 500: seis cidades & 3,51 \\
\hline & + de 500: Rio de Janeiro + duas cidades & 10 \\
\hline & Total & 13,7 \\
\hline \multirow[t]{3}{*}{ Espírito Santo (capital + oito cidades) } & De 50 a 100: duas cidades & 0,23 \\
\hline & De 100 a 500: Vitória + seis cidades & 3,67 \\
\hline & Total & 3,9 \\
\hline \multirow[t]{6}{*}{ São Paulo (105 cidades + capital) } & Até 20: 16 cidades & 0,5 \\
\hline & De 20 a 50: 29 cidades & 1,33 \\
\hline & De 50 a 100: 26 cidades & 2,48 \\
\hline & De 100 a 500: 30 cidades & 13,9 \\
\hline & + de 500: cinco cidades + São Paulo & 18,5 \\
\hline & Total & 36,7 \\
\hline
\end{tabular}

Fonte: elaboração própria, com base em BNDES 2015 (pedido de informação n. 99903000073201580) e contagem populacional do IBGE. 
Tabela 2B - Contratos por região, porte populacional e porcentual de financiamento do BNDES (Sul)

\begin{tabular}{|c|c|c|}
\hline Estado (cidades) & Porte populacional (mil/habitantes) & Percentual financiado \\
\hline \multirow[t]{6}{*}{ Paraná (capital + 36 cidades) } & Até 20: 13 cidades & 0,19 \\
\hline & De 20 a 50 : cinco & 0,21 \\
\hline & De 50 a 100: oito cidades & 0,67 \\
\hline & De 100 a 500: 10 cidades & 2,81 \\
\hline & + de 500: Curitiba & 0,94 \\
\hline & Total & 4,82 \\
\hline \multirow[t]{5}{*}{ Santa Catarina (44 cidades + capital) } & Até 20: 20 cidades & 0,32 \\
\hline & De 20 a 50: 10 cidades & 0,44 \\
\hline & De 50 a 100: seis cidades & 0,53 \\
\hline & $\begin{array}{l}\text { De } 100 \text { a } 500: \text { nove cidades }+ \\
\text { Florianópolis }\end{array}$ & 3,5 \\
\hline & Total & 4,79 \\
\hline \multirow[t]{5}{*}{ Rio Grande do Sul (27 cidades) } & Até 20: quatro cidades & 0,05 \\
\hline & De 20 a 50: seis cidades & 0,3 \\
\hline & De 50 a 100: sete cidades & 0,69 \\
\hline & De 100 a 500: dez cidades Total & 5,24 \\
\hline & Total & 6,28 \\
\hline
\end{tabular}

Fonte: elaboração própria, com base em BNDES 2015 (pedido de informação n. 99903000073201580) e contagem populacional do IBGE.

Tabela 2C - Contratos por região, porte populacional e porcentual de financiamento do BNDES (Nordeste)

\begin{tabular}{|c|c|c|}
\hline Estado (cidades) & Porte populacional (mil/habitantes) & Percentual financiado \\
\hline \multirow[t]{6}{*}{ Ceará (capital + 19 cidades) } & Até 20: duas cidades & 0,04 \\
\hline & De 20 a 50: sete cidades & 0,3 \\
\hline & De 50 a 100: nove cidades & 0,67 \\
\hline & De 100 a 500: uma cidade & 0,28 \\
\hline & + de 500: Fortaleza & 0,46 \\
\hline & Total & 1,75 \\
\hline \multirow[t]{5}{*}{ Bahia (sete cidades) } & Até 20: uma cidade & 0,02 \\
\hline & De 20 a 50: uma cidade & 0,37 \\
\hline & De 50 a 100: uma cidade & 0,07 \\
\hline & De 100 a 500: quatro & 0,71 \\
\hline & Total & 1,17 \\
\hline \multirow[t]{3}{*}{ Paraíba (capital e uma cidade) } & De 100 a 500: uma cidade & 0,12 \\
\hline & De 100 a 500: João Pessoa & 0,77 \\
\hline & Total & $\mathbf{0 , 8 9}$ \\
\hline \multirow[t]{4}{*}{ Piauí (capital + três cidades) } & Até 20: duas cidades & 0,03 \\
\hline & De 100 a 500: uma cidade & 0,19 \\
\hline & + de 500: Teresina & 0,29 \\
\hline & Total & $\mathbf{0 , 5 1}$ \\
\hline \multirow[t]{2}{*}{ Pernambuco (capital e + seis cidades) } & De 50 a 100: uma cidade & 0,05 \\
\hline & De 100 a 500: cinco cidades & 0,9 \\
\hline
\end{tabular}


Tabela 2C (cont.)

\begin{tabular}{llc}
\hline Estado (cidades) & Porte populacional (mil/habitantes) & Percentual financiado \\
\hline & + de 500: Recife & 0,52 \\
& Total & $\mathbf{1 , 4 7}$ \\
Maranhão (capital + uma cidade) & De 50 a 100: uma cidade & 0,31 \\
& Mais de 500: São Luís & 0,43 \\
& Total & $\mathbf{0 , 7 8}$ \\
\hline
\end{tabular}

Fonte: elaboração própria, com base em BNDES 2015 (pedido de informação n. 99903000073201580) e contagem populacional do IBGE.

Tabela 2D - Contratos por região, porte populacional e porcentual de financiamento do BNDES (Centro-Oeste)

\begin{tabular}{llc}
\hline Estado (cidades) & $\begin{array}{l}\text { Porte populacional } \\
\text { (mil/habitantes) }\end{array}$ & Percentual financiado \\
\hline Mato Grosso (17 cidades) & Até 20: sete cidades & 0,16 \\
& De 20 a 50: seis cidades & 0,31 \\
& De 50 a 100: duas cidades & 0,19 \\
& De 100 a 500: uma cidade & 0,24 \\
& Total & $\mathbf{0 , 9}$ \\
Mato Grosso do Sul (capital + uma cidade) & + de 500: Campo Grande & 0,11 \\
& De 50 a 100: uma cidade & 0,14 \\
& Total & $\mathbf{0 , 2 5}$ \\
Goiás (três cidades) & Até 20: duas cidades & 0,04 \\
& De 50 a 100: uma cidade & 0,07 \\
\hline
\end{tabular}

Fonte: elaboração própria, com base em BNDES 2015 (pedido de informação n. 99903000073201580) e contagem populacional do IBGE.

Tabela 2E - Contratos por região, porte populacional e porcentual de financiamento do BNDES (Norte)

\begin{tabular}{llc}
\hline Estado (cidades) & Porte populacional (mil/habitantes) & Percentual financiado \\
\hline Rondônia (capital + três cidades) & De 20 a 50: uma cidade & 0,03 \\
& De 50 a 100: duas cidades & 0,21 \\
& De 100 a 500: Porto Velho & 1,17 \\
& Total & $\mathbf{1 , 4 1}$ \\
Acre (capital e uma cidade) & De 50 a 100: uma cidade & 0,12 \\
& De 100 a 500: Rio Branco & 3,58 \\
Pará (duas cidades + capital) & Total & $\mathbf{3 , 7}$ \\
& De 100 a 500: duas cidades & 0,53 \\
+ de 500: Belém & 1,53 \\
Amazonas (capital) & Total & $\mathbf{2 , 0 6}$ \\
Tocantins (capital) & Te $500:$ Manaus (capital) & 4,33 \\
& Total & $\mathbf{4 , 3 3}$ \\
& De 100 a 500: Palmas & 0,25 \\
\hline
\end{tabular}

Fonte: elaboração própria, com base em BNDES 2015 (pedido de informação n. 99903000073201580) e contagem populacional do IBGE. 
2 Com mais de um contrato: Belo Horizonte e Rio de Janeiro (quatro vezes), Sorocaba (três vezes) (SP), Belém (PA), Caxias do Sul, Pelotas e São Leopoldo (RS), Florianópolis e Itajaí (SC), Foz do Iguaçu (PR), Ipatinga (MG), Diadema, Jacareí, Jundiaí, Mogi das Cruzes, Salto, São Bernardo do Campo, São José do Rio Preto, Santos (SP), Vila Velha e Vitória (ES), Manaus (AM) e Rio Branco (AC) (duas vezes).

\footnotetext{
3 Para mais informações sobre as exigências legais e administrativas de adesão municipal ver Grin (2014), BNDES (2009; 2011) e o Manual de Instrução dos Pleitos (MIP) (STN, 2011).
}

causas da assimetria de acesso é a adesão voluntária como o jogo cooperativo disponível: optaram pela candidatura as cidades "mais bem preparadas" (Wright, 1988; Terman et al., 2016).

Os municípios das regiões Norte, Nordeste e Centro-Oeste cobriram $15,63 \%$ dos valores financiados pelo BNDES, afora as contrapartidas locais, enquanto as regiões Sul e Sudeste contrataram $84,4 \%$ do total. Em termos de porte populacional, os municípios com até 50 mil habitantes responderam por 42,6\% dos contratos (144 operações), embora representem apenas 4,68\% dos valores totais financiados. Portanto, os municípios acima de 50 mil habitantes, que são $11 \%$ do total no Brasil, apropriaram-se de 95,3\% das disponibilidades financeiras do PMAT. Mas mesmo entre os pequenos municípios houve concentração regional: 81,2\% no Sul e Sudeste, respectivamente Paulo $(31,3 \%)$, Santa Catarina $(20,8 \%)$ e Paraná $(12,5 \%)$ responderam por quase dois terços.

Outra forma de avaliar a concentração dos recursos são os 23 municípios (capitais e aqueles acima de 150 mil habitantes) que captaram 46,3\% do total. Se a esses forem adicionados os valores de São Paulo capital, a soma chega a 55,2\%. Assim, 24 municípios financiaram mais de 50\% de todos os valores contratados, lembrando que são localidades que, comparativamente às menores, possuem mais capacidades estatais ${ }^{2}$. Mesmo as alternativas para simplificar o acesso diante do reconhecimento do baixo número de adesões, como foi o PMAT Especial, não lograram êxito, pois apenas oito municípios aderiram a essa modalidade até 2011. Este é um exemplo de como o mecanismo da dissonância federativa operou: redefinições normativas ocorreram de forma centralizada e somente pela burocracia técnica do BNDES. A resposta dos municípios não poderia ser mais evidente como expressão das visões contrastantes entre o doador federal e os destinatários municipais.

O otimismo do programa como política pública para modernizar a gestão local foi pouco efetivo em termos de cooperação federativa, uma vez que na distribuição regional e financeira esse processo virtualmente inexistiu. A policy interaction (Agranoff, 2007) foi pouco efetiva, pois os municípios não se alinharam equitativamente dentro das estipulações legais e regulatórias, já que regras inseridas em políticas constrangem as escolhas de atores políticos (Skocpol, 2002; Immergut, 1990; 1998). O programa exigia uma ampla documentação (certidões negativas de débito com relação a tributos federais, dívida ativa com a União e Certificados de Regularidade Previdenciária e do FGTS) ${ }^{3}$. Como esta não é a realidade da maioria dos municípios, sobretudo dos menores, ela também contribuiu para restringir a procura pelo PMAT.

O município deveria indicar os bens oferecidos em garantia como reserva de pagamento que, em geral, recaía sobre as cotas-parte do Fundo de Participação dos Municípios (FPM) e/ou receitas provenientes do Imposto sobre Circulação de Mercadorias e Serviços (ICMS) ou ICMS-Exportação sem a certeza de que reduziria despesas e ampliaria receitas próprias. Requeria-se apresentar o impacto do projeto na arrecadação própria, com seus indicadores de avaliação e premissas utilizadas para elaborar a projeção do IPTU e o ISS. Isso devia-se à prioridade atribuída para o aumento da receita como base de modernização da gestão municipal (Guarneri, 2002).

Estas demandas acabaram incidindo para que capitais e municípios de maior porte fossem os maiores beneficiários. Estes costumam ter relação direta com o BNDES e uma situação fiscal com maior capacidade de arrecadação, além de serem menos dependentes do FPM (Grin, 2014). Portanto, o "risco de não obediência" (Wright, 1988) dos regulamentos gerou um trade-off entre aderir/não aderir (Agranoff \& McGuire, 2004) que penalizou especialmente os menores municípios. Este procedimento era o mesmo para todas as operações 
do Banco que, por serem muito onerosas, acabavam sendo mais compensadoras para os maiores municípios (entrevista 1).

Além das exigências legais e financeiras, as cidades precisavam considerar o tempo de contratação: a) análise da liberação do recurso pelo BNDES e permissão prévia (180 dias) e b) análise da situação fiscal (a Secretaria do Tesouro Nacional (STN) avaliava o atendimento aos requisitos do MIP e se havia capacidade de pagamento). Inexistindo mudanças nos valores, a STN levava de oito meses a um ano para concluir sua análise. O projeto recebia uma análise operacional para verificar se atendia as diretrizes do BNDES e se havia capacidade de pagamento, antes de chegar nos colegiados da diretoria para a sua avaliação final (entrevista 6).

Todo processo podia estender-se por quase dois anos (nas 366 operações contratadas a diferença entre a data da autorização e sua contratação foi de 11,6 meses). Com efeito, mesmo decisões técnicas dos subgovernos como o BNDES e a STN geram efeitos intergovernamentais que foram mais deletérios para os menores municípios. Como desenho institucional e regas inseridas em políticas públicas importam (Pierson, 1993; 2004; Immergut, 1990; 1998; Skocpol, 2002), seus efeitos em termos de não adesão foram mais pronunciados nos menores municípios das regiões e estados menos desenvolvidos.

Estes requerimentos influíram nas adesões em face da inflexibilidade das normas e dos constrangimentos gerados pela legislação e procedimentos burocráticos requeridos (Pressman, 1975; Skocpol, 2002). Quanto menor o município, mais dependentes de recurso do FPM e maior suas carências administrativas e técnicas para atender as exigências do MIP/STN para obter o financiamento.

Frente a essa situação, os municípios adotaram um comportamento calculador (Wright, 1988) dos custos e benefícios. Por exemplo, o trade-off entre o risco de perda de receitas como o FPM e a aposta em gerar resultados por meio do PMAT. Essa é uma forma de observar o mecanismo da dissonância federativa (Downs, 1967; Conlan \& Posner, 2016) em funcionamento: para os feds os municípios são cautelosos e tímidos, ao passo que em nível local a visão dos gestores federais é vista como imprudente, já que requerem garantias que podem comprometer suas receitas. A distribuição regional das adesões e a apropriação financeira municipal reforça esse argumento: localidades com mais capacidades estatais, além de menos dependentes do FPM, são mais habilitadas para atenderem as exigências legais. Por seu turno, aquelas que apresentassem pendências junto aos órgãos federais ficavam impedidas de contratar o programa.

Em linha com Agranoff (2007), houve uma distância entre o formato do programa, alinhado à legislação sobre o crédito público no Brasil, e as dificuldades de adesão local, o que influiu na sua desigual apropriação federativa. Há uma "neurose" para empréstimos públicos, ainda que a Resolução 2.827 (artigo 9) do CMN descontigenciasse os valores do PMAT para, em tese, facilitar o acesso a essa linha de crédito (entrevista 5). Mas, na prática, poucos municípios estavam em condições de acessar esse programa, pois o rito legal eliminava boa parte da clientela potencial, sobretudo os menores. Esta complexa apresentação da candidatura e suas "as amarras" (Pressman, 1975) era conhecida pelo BNDES quando realizou uma avaliação do programa:

"Cumpre esclarecer que [...] fatores críticos na implementação das ações de modernização, como a existência de um arcabouço regularizador complexo e dinâmico em relação ao endividamento do setor público que [...] dificulta, e por vezes impede, a concessão do crédito. Adicionalmente, a concepção e a execução de um projeto com esse grau de complexidade nas transformações configuram-se um desafio, por vezes insuperável, para alguns municípios [dado o] 
quadro de deterioração no qual se encontra grande parte das administrações públicas municipais [...]” (Guarneri, 2002, p. 34).

Em outro momento, constatou-se que:

\begin{abstract}
"O BNDES pode assumir a responsabilidade de contribuir gradativamente, e em acordo com as especificidades locais, para a melhoria da qualidade de gestão nas áreas sociais dos governos estaduais e municipais. [O] espaço de atuação do Banco pode se concentrar no reforço da função de planejamento, no uso intenso de tecnologia para ganhar produtividade e na capacitação de mão de obra [...]. Na medida em que, apesar da evidente e premente necessidade, os agentes públicos revelam dificuldades para formatar projetos de modernização de gestão, caberia ao Banco aprimorar a sua gestão interna de conhecimento e construir mecanismos de desenvolvimento institucional e de incentivo à estruturação da demanda nessa área" (Henriques \& Reiff, 2010, p. 367).
\end{abstract}

Um dos principais entraves residiu na dificuldade de os municípios elaborarem projetos para o BNDES, mesmo com as medidas simplificadoras como foram o PMAT Especial (de 2008 a 2011) e o PMAT Automático (de 2011 a 2014). Se a análise do Banco coincidiu com as limitações para os municípios atenderem aos requisitos legais, gerenciais, administrativos e financeiros, não deixou de ser um contrassenso manter a entrega de um amplo planejamento prévio que, a rigor, deveria ser um resultado do programa e não um pré-requisito de acesso. Com efeito, a carência de "capacidade de absorção" (Pressman, 1975 ) municipal também foi um obstáculo para a obtenção do financiamento.

Segundo Peterson (1995), esse seria um dos preços a pagar pelo federalismo para as cidades melhorarem a prestação de serviços, o que requer capacidades de planejamento e qualidade de recursos humanos. Dessa maneira, não importa apenas o conteúdo dos programas de apoio, mas também suas regras de acesso e a forma como são definidas (Pierson, 1993; 2004), porque isso ajuda a compreender como são administrados, franqueiam adesões e influem nos resultados que geram. No caso do PMAT houve pouca pactuação federativa sobre o seu desenho e prevaleceu a tradição administrativa da burocracia técnica atuando como um subgoverno (Wright, 1988), bem como controlando as regras administrativas sobre as quais o BNDES tinha autonomia para decidir.

Diante do desenho institucional do PMAT, considerando a combinação das exigências para o ingresso municipal e o fato de as candidaturas serem voluntárias, as induções geradas pelas regras do programa (Immergut, 1990; 1998; Skocpol, 2002) favoreceram majoritariamente os maiores municípios. Em termos da cooperação federativa para promover capacidades estatais, o resultado, ao menos em termos da assimetria de acesso, favoreceu as cidades mais afluentes. A dissonância federativa (Downs, 1967; Conlan \& Posner, 2016) entre o BNDES e os municípios é o que explica a realidade das adesões.

\section{O otimismo do PMAT e a realidade das adesões municipais: as visões contrastantes dos gestores federais e dos governos municipais}

Esta seção coteja a visão dos gestores do PMAT no BNDES e Caixa Econômica Federal (CEF) com a posição das associações nacionais de representação dos municípios (ABM, CNM e FNP). O objetivo é mostrar como o desenho do programa com suas regras (Skocpol, 2002; Immergut, 1990; 1998) gerou diferentes leituras sobre seus custos e benefícios que, ao fim e ao cabo, afetaram a cooperação federativa (Elazar, 1972; Agranoff \& Radin, 2014) para promover as capacidades estatais municipais. Discutem-se os efeitos do mecanismo da dissonância federativa (Downs, 1967; Conlan \& Posner, 2016). Para os proponentes do programa este permitia às cidades encaminharem soluções para seus problemas fiscais e administrativos: 
"A grande aceitação desse programa vem demonstrando o compromisso dos governos municipais com a modernização da gestão nas áreas tributária, financeira, administrativa e nos setores sociais básicos (Guarneri, 2002, p. 2).

Tais projetos visam à modernização da administração tributária e melhoria da qualidade do gasto público, proporcionando aos municípios uma gestão eficiente de recursos, em especial, por meio do aumento das receitas e da redução do custo unitário dos serviços em administração geral, saúde e educação" (BNDES, 2013, p. 6).

“[O] PMAT destina-se à modernização da administração tributária e à melhoria da qualidade do gasto público [...], visando proporcionar aos municípios brasileiros possibilidades de atuar na obtenção de mais recursos estáveis e não inflacionários, e na melhoria da qualidade e redução do custo praticado na prestação de serviços nas áreas de administração geral, assistência a crianças e jovens, saúde, educação e de geração de oportunidades de trabalho e renda" (BNDES, 2009, p. 5).

O desempenho do programa mostrou um panorama menos otimista, pois o seu alcance federativo, distribuição regional e concentração de recursos indicam que esta visão do BNDES não logrou êxito. Entre a imagem do PMAT e o número de contratações residem muitas expectativas não cumpridas, sobretudo das cidades que eram as potenciais destinatárias, pois dadas as condições de acesso, houve um hiato entre a promessa e a performance da ajuda federal. O intercâmbio entre o doador e donatário (Presmann, 1975) não se desenvolveu conforme a narrativa oficial e a posição dos feds não coincidiu com as possibilidades das cidades.

Pela ótica dos doadores federais, o baixo acesso municipal derivava da falta de conhecimento para elaborar projetos requeridos para contratar o programa. Assim, é parcialmente verdadeiro que as exigências da STN atrasavam o processo, pois essas são idênticas em todas as operações de crédito público. $\mathrm{O}$ desafio municipal foi menos o alcance a recursos, que estavam disponíveis, mas sua baixa capacidade gerencial para elaborar projetos, o que gerou assimetria de acesso ao programa (entrevistas 1, 2 e 6).

Segundo os municípios, a dificuldade para contratar decorria dos exageros impostos pela "tecnocracia" - os imperativos funcionais, nos termos de Agranoff (2001). Na falta de uma instância federativa para lidar com o diálogo fiscal, coube à STN aplicar as regras válidas para os municípios. "A quantidade de demandas para ter autorizada uma operação de crédito é insana e insustentável, pois o MIP/STN apresenta exigências sem o menor cabimento em termos práticos. O MIP é manual de instrução para que não se consiga emprestar" (entrevista 5). As posições sobre o MIP/STN não coincidiram, pois para os gestores federais entrevistados o manual padronizou documentos para verificar se o município atende a LRF (entrevistas 1 e 6).

Os prefeitos reclamavam da complexidade da tramitação do PMAT por ser muito custoso obter qualquer suporte do BNDES (entrevistas 3 e 4). Para os gestores federais, a simplicidade nos processos tornava injustificável a falta de propostas dos municípios.

"Por exemplo, um município quer trocar 100 computadores e pode pagar em seis anos com mais dois de carência se utilizasse o PMAT Automático (máquinas e equipamentos). Se o PMAT permite, por que os municípios não o utilizam para trocar seu parque de computadores e seus servidores? E nesse caso nem é necessário elaborar projeto, pois basta preencher uma folha! O que ocorre é que eles preferem as verbas não reembolsáveis como as emendas parlamentares" (entrevista 6)

Para ampliar o acesso ao programa, o PMAT necessitava aumentar seu conhecimento junto aos municípios, apesar da sua divulgação pela internet 
(entrevistas 3, 4, 5). De forma oposta, para os gestores federais, com os vários eventos que os municípios participam, desconhecimento não podia ser uma desculpa para não acessar o financiamento, mas sim a falta de interesse associado às carências financeiras e organizativas (entrevista 6). O survey mostra que quase $50 \%$ dos municípios desconhecia o programa. Para os municípios foi difícil ajustar o PMAT à sua realidade. Apesar da baixa qualificação gerencial, inexistiu um sistema público que apoiasse os municípios a elaborarem projetos que ampliassem suas chances de buscar recursos (entrevistas 3, 4). Por essa ótica, o programa via conexões inexistentes com a realidade local (Brendan, 2014; Wright, 1988).

Alguns municípios precisam de busca ativa, embora o Governo Federal não compreenda, pois baseia-se no seguinte jargão:

"Se não tem projeto, não tem dinheiro, precisa fazer o projeto e vir pedir, se não pedir não vai ter". [...]. Será preciso chegar em alguns e falar: "prefeito, PMAT é isso, o senhor vai conseguir pagar, para o pré-projeto nós vamos disponibilizar para o senhor alguns técnicos que vão ficar aqui para ajudar" (entrevista 5).

Distinta é a visão dos gestores federais, dado que o PMAT Automático alcançou um número maior de cidades com operações de menor porte ao simplificar as regras que facilitaram sua proposição e acompanhamento (entrevista 2). Para os gestores federais, com o receio de comprometer receitas, os municípios demandavam mais repasse de FPM, de sorte que:

“A visão local não é de `eu quero crédito’, mas é de `eu quero dinheiro de graça". Como os menores resistem mais em cobrar impostos, costumam optar pela busca de "dinheiro de graça" do governo federal. Não apenas tentam fugir de contrapartidas requeridas em financiamentos, mas também das exigências do CAUC/STN. Demandam, por exemplo, [...] repasses não reembolsáveis, sem a necessidade de pagamentos ou que exijam executar "maldades" julgadas impopulares, tal como cobrar impostos. Falta uma cultura da busca de financiamento, embora com um PMAT bem executado os impostos gerados poderiam facilmente pagar o investimento em dois anos de arrecadação (entrevista 1).

Mesmo em questões onde há acordo entre feds e locals a análise difere, como no caso da exigência de apresentar um projeto para análise técnica do BNDES. Para os $f e d s$, essa é uma tarefa onerosa que requer profissionais especializados. Esta não é a realidade das prefeituras pequenas, mas sim a situação daquelas acima de 100 mil habitantes (entrevista 6). Para os municípios, diante dessa limitação, é insuficiente divulgar que os prazos de pagamento são longos, o período de carência é bom e que se houver o projeto obterá o financiamento. Segue sendo demandada capacidade técnica que raramente existe localmente (entrevistas 3, 4 e 5). Tem-se aqui um exemplo do "efeito das imagens contrastantes" entre feds e locals (Pressman, 1975; Downs, 1967).

Quanto à forma como o Serviço Auxiliar de Informações para Transferências Voluntárias (CAUC/STN) se relacionava com os municípios também havia dissonâncias. Para os feds, a legislação sobre operações de crédito público é complexa para ser atendida, porém "um prefeito não pode dizer que desconhece apontamentos sobre a situação de seu município. Isto é falacioso, pois basta ele inserir o CNPJ do município no site do CAUC" (entrevista 1). Para os municípios, deveria ser facilitado o acesso às suas informações cadastrais, pois muitas vezes os apontamentos são arbitrários, embora sejam meras questões burocráticas. Não há avisos: "olha, caso tal documento não for entregue até tal data. [...]. Outra coisa é descobrir o que é, o que acarreta sabe-se lá quantos dias para consertar [...]" (entrevista 5).

As visões contrastantes marcaram a relação entre os gestores do PMAT e os municípios. A forma como um programa é apresentado pode induzir uma compreensão de mais vantagens ou desvantagens pelos potenciais beneficiá- 
rios, a depender da imagem criada a partir de suas regras, exigências e meios de acesso (Grodzins, 1984). Os policy makers federais julgam ter o dever de propor oportunidades e expressar objetivos de alcance intergovernamental (Derthick, 1972). Creem que precisam demonstrar a outras esferas de governo o que deve ser feito por meio dos projetos que conceberam. Embora os efeitos tangíveis restrinjam-se a algumas localidades, acredita-se que ele pode beneficiar um público mais amplo.

O caso do PMAT evidencia como opera o mecanismo da dissonância federativa que influenciou a cooperação intergovernamental e revelou poucos pontos de aderência entre os feds e os locals. Para os subgovernos federais, as cidades veem barreiras e constrangimentos (Downs, 1967) para repassar a responsabilidade ao BNDES e STN pela não adesão ao programa. Já os municípios julgam que o PMAT pouco compreendeu sua realidade. Esta dissonância contribuiu para gerar uma assimetria de acesso (Pressman, 1975) que foi aproveitada pelos maiores municípios os quais, em termos relativos, possuem mais capacidades e menos necessidades (Wright, 1988; Terman et al., 2016). Com o seu formato, regras de indução e desacordos sobre seu funcionamento, em termos federativos, o programa foi pouco exitoso como via de acesso para a grande maioria das cidades.

\section{O PMAT pela ótica dos gestores municipais}

${ }^{4}$ Nessa questão, a amostra tem $94 \%$ de confiança e margem de erro $5 \%$.
Essa seção se baseia nas informações do survey respondido pelos dirigentes municipais das secretarias de Finanças e/ou Administração de 328 municípios e sobre duas questões: possibilidade da candidatura e áreas prioritárias do programa. A primeira avalia o interesse em função da necessidade percebida (Wright, 1988). A segunda é o conceito de "federalismo de velocidade variável": governos subnacionais podem concordar com os objetivos das políticas federais, mas sua implementação ocorre de distintas maneiras (Conlan \& Posner, 2016).

O PMAT era conhecido por $53 \%$ dos municípios ${ }^{4}$ (sendo $78 \%$ mais de 50 mil habitantes), de forma que o objetivo da cooperação intergovernamental conviveu com um desconhecimento de quase metade dos municípios, sobretudo os menores. Este é mais um fator que incidiu sobre a assimetria de acesso em favor das cidades com mais capacidades institucionais e, geralmente, mais informadas sobre o programa.

Houve uma demanda significativa que não foi atendida pelo programa, tal como fica evidenciado na Tabela 3.

Assim, "tanto a medida das necessidades dos candidatos ou destinatários e de sua capacidade administrativa mostram sistemática associação com a alocação de ajuda" (Wright 1988, p. 237). Mas a questão é saber se essas duas condições caminham juntas, pois geralmente quanto mais necessitados, menos capacidade estatal possuem os municípios. Conforme a pesquisa, das cidades

Tabela 3 - Interesse dos municípios em contratar o PMAT

\begin{tabular}{lcc}
\hline Opções de resposta $^{\mathrm{I}}$ & Porcentual $^{\mathrm{II}}$ & Contagem $^{\mathrm{I}}$ \\
\hline Sim & 83 & 73 \\
Não & 17 & 15 \\
Total & 100 & 88 \\
\hline
\end{tabular}

Fonte: Pesquisa realizada junto aos municípios brasileiros (outubro-dezembro de 2015). IResposta para a pergunta: "Caso ainda não tenha apresentado uma proposta de submissão do PMAT, o município tem interesse?"

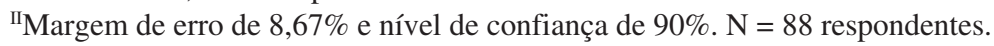


interessadas, 73,5\% possuíam até 50 mil habitantes. Mas a demanda potencial não coincidiu com a realidade das contratações e, por esse quesito, o programa foi pouco eficaz para promover capacidades estatais nas menores localidades.

Na Tabela 4 é possível verificar o porcentual de municípios que apresentaram propostas para o PMAT. Dos que lograram submeter um projeto, a taxa de sucesso foi de $32,6 \%$, (14 contrataram o programa).

Também por esse aspecto, a eficácia na gestão do programa não foi alentadora. Há nesse indicador muito de "expectativas não cumpridas" junto aos potenciais destinatários do programa (Pressman, 1975), o que reforça a distância entre a promessa e a performance da ajuda federal.

As razões do pouco interesse assemelham-se àquelas apontadas por (Kane, 1984) ao avaliar se os requerimentos para obter grants and funds alinhavam-se à realidade administrativa municipal americana (apresentadas na Tabela 5).

A maioria das cidades não aderiu aos programas frente às exigências das regras de acesso (Skocpol, 2002; Immergut, 1990; 1998). No caso do PMAT, essa foi a razão central para $34,6 \%$ das cidades. Se a essa forem associadas alternativas afins (rigidez das normas, receio de perder o FPM e condições de pagamento desfavoráveis), mais de $81 \%$ de respostas abordaram dificuldades relacionadas às normas do programa. Sem falar dos $24,7 \%$ que, por recearem não gerar resultados, parecem adotar uma postura defensiva e os $21 \%$ que

Tabela 4 - Apresentação de proposta para obter o PMAT

\begin{tabular}{lcc}
\hline Opções de resposta $^{\mathrm{I}}$ & Porcentual $^{\mathrm{II}}$ & Contagem $^{\mathrm{I}}$ \\
\hline Sim & 37,4 & 43 \\
Não & 62,6 & 72 \\
Total & 100 & 115 \\
\hline
\end{tabular}

Fonte: Pesquisa realizada junto aos municípios brasileiros (outubro-dezembro de 2015). IResposta para a pergunta: "O município já apresentou uma solicitação para obter o financiamento do PMAT?"

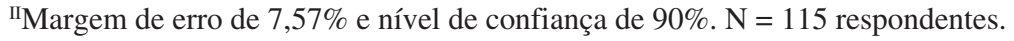

Tabela 5 - Razões da falta de interesse dos municípios em contratar o PMAT

\begin{tabular}{|c|c|c|}
\hline Opções de resposta ${ }^{\mathrm{I}}$ & Porcentual $^{\mathrm{II}}$ & Contagem \\
\hline Regras e normas do projeto são muito difíceis para a cidade cumprir & 34,6 & 28 \\
\hline Falta pessoal qualificado no governo para elaborar um bom projeto & 29,6 & 24 \\
\hline A cidade não pode contratar um projeto caro sem saber se dará retorno & 24,7 & 20 \\
\hline $\mathrm{O} \mathrm{BB} / \mathrm{CEF} / \mathrm{BNDES}$ demoram para dar retorno aos municípios & 21 & 17 \\
\hline As condições de pagamento do financiamento não são favoráveis & 18,5 & 15 \\
\hline O programa é muito rígido nas suas regras de utilização & 13,6 & 11 \\
\hline Receio de ficar com quota-parte do FPM retida se não pagar o financiamento & 13,6 & 11 \\
\hline O município deve para o governo federal e não pode receber verbas & 6,2 & 5 \\
\hline Não há condições de aproveitar/adaptar suas ações na realidade local & 3,7 & 3 \\
\hline
\end{tabular}

Fonte: Pesquisa junto aos municípios (outubro-dezembro de 2015). $\mathrm{N}=81$ respondentes.

IResposta para a pergunta: "Caso não tenha apresentado uma proposta de submissão do PMAT, por que o município não tem interesse?"

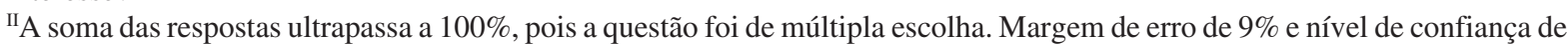
$90 \%$. 
reclamam da demora na tramitação dos projetos. Houve, portanto, uma "velocidade variável" de adesão em função das regras do programa.

Os municípios avaliaram que os custos do programa eram elevados, ainda que para aqueles com até 150 mil habitantes o BNDES financiava $100 \%$. Apesar de ser correto argumentar que a TJLP gerava juros baixos, e não limitava o acesso (entrevista 1), a percepção de $24,7 \%$ dos municípios é diferente. E esse é um problema de desconhecimento e do campo diferencial de jogo (Wright, 1988) entre o BNDES e os municípios. Ainda que objetivamente as condições do programa fossem acessíveis, sua imagem junto às cidades está em linha com o mecanismo explicativo. O otimismo dos dirigentes do PMAT de que se tratava de financiamento acessível esteve em desacordo com a visão das localidades.

\section{Conclusão}

A pesquisa mostrou como jogos da cooperação federativa podem resultar em visões contrastantes entre feds e locals. Empiricamente, essa discussão baseou-se na implementação do PMAT e como o mecanismo explicativo da dissonância federativa permite compreender a relação entre "doador" e "destinatário" no bojo das relações intergovernamentais. Como analisado, o resultado da cooperação federativa foi o oposto do que propugnava sua visão mais benigna, pois incentivou ações mais defensivas na maioria dos municípios que ponderaram custos e benefícios do acesso ao PMAT (Agranoff \& McGuire, 2004; Terman et al., 2016).

A ação dos subgovernos assume relevância se os proponentes da política podem moldar a cooperação intergovernamental ao combinarem sua autonomia funcional com capacidade de enforcement na implementação de regras de acesso (Wright, 1988; Pressman, 1975; Wright \& Stenberg, 2007; Biesbroek, Peters \& Tosun, 2018). No caso do PMAT, essas normas pouco consideraram as desigualdades municipais, o que favoreceu a candidatura dos "mais aptos". Como a realidade das relações intergovernamentais costuma não ser homogênea, prescrições de programas (Skocpol, 2002; Immergut, 1990) podem implicar distintos padrões de vínculos e produzir diferentes impactos nas localidades (Wright,1988; Kim McDonald \& Lee, 2016). Nesse caso, as regras do programa incentivaram a cartelização e o monopólio de acesso (Elazar, 1994).

A dissonância federativa reduziu as possibilidades de o PMAT promover capacidades estatais municipais. As divergentes visões de feds e os locals mostram como tensões entre controle central e autonomia local geram problemas na cooperação federativa. Importa o quanto o BNDES foi consciente desse jogo, pois o programa incentivou os mais "habilitados" em detrimento dos mais "necessitados" (Grodzins, 1984; Kane, 1984). O PMAT pouco fez para reduzir essas disparidades, pois argumentar que os municípios são autônomos para decidirem suas candidaturas não alterou o status quo das desigualdades entre esses entes. A carência local de "capacidade de absorção" (Pressman, 1975) foi um limitador para a maioria das cidades receberem apoio federal, ainda que a demanda existisse, conforme o survey mostrou.

Os municípios deixaram de lado a busca de apoio governamental e optaram por um comportamento mais defensivo (Wright, 1988), e para a grande maioria seguiu inexplorada a possibilidade de contratar o PMAT. Aproximar as visões de feds e locals, e o trade-off entre aderir ou não ao programa, ampliaram as dissonâncias federativas, mesmo que em detrimento das demandas para modernizar a gestão municipal. 
A visão dos gestores no Ministério da Fazenda, CEF e BNDES mostrou-se distinta, quando não oposta, àquela manifestada pelos municípios. Os achados da pesquisa confirmam o que a literatura aponta como problemas que surgem em situações de dissonância federativa. "Risco de não obediência" (Wright, 1988), "inflação de objetivos" (Derthick, 1972), "irrealismo otimista" (Downs, 1967) e "falta de capacidade de absorção" (Pressman, 1975) podem gerar leituras antagônicas entre os entes federativos sobre um mesmo programa. Como foi visto, diferentes opiniões adquirem uma objetividade que, se não impede, dificulta a cooperação federativa, pois "constrangimentos estruturais" limitam as chances de intercâmbio entre as esferas governamentais (Downs, 1967).

Muitos municípios não se ajustaram ao PMAT, pois a formulação centralizada de suas regras não foi vista como estímulo à cooperação (Derthick, 1972). Pelo contrário, a adesão local foi pouco efetiva para equilibrar a necessidade percebida vs. disponibilidade de financiamento e capacidade administrativa para desenvolver a candidatura e a estimada probabilidade de sucesso (Wright, 1988). Suas regras geraram uma apropriação desigual e uma assimetria de acesso em favor dos maiores municípios, pois necessidades locais acabaram secundarizadas em favor das condições de pagamento das cidades mais afluentes junto ao BNDES.

Esta pesquisa possui limitações quanto aos seus achados, que podem orientar outras pesquisas. $\mathrm{O}$ foco analítico esteve em identificar como e porque o desenho institucional do PMAT como variável independente gerou como efeito uma baixa adesão da grande maioria dos municípios, sobretudo dos menores. Não foram discutidas questões de ordem local que também podem influenciar as escolhas municipais de participar ou não em um programa como esse. Portanto, outros estudos podem avaliar se variáveis políticas e administrativas (por exemplo, competição política, liderança, composição do legislativo, profissionalização da burocracia, e.g.) também podem ter papel explicativo no interesse dos governos municipais em desenvolver suas capacidades estatais.

Como lembra Agranoff (2001, p. 39), o objetivo "de governos capazes trabalhando juntos como um meio de manter a federação" pode se deparar com a distância entre o formato de programas e a divisão criada entre "aptos"/"não aptos" e "interessados"/“não interessados". A pesquisa mostrou que programas federais como o PMAT, substancialmente definidos por subgovernos, como ocorreu com o BNDES, são mais prováveis de serem ineficazes para incentivar a adesão municipal para promover suas capacidades estatais. Dissonâncias federativas gerada pelas distintas visões de fed e locals explicam esse processo. Isso diz muito sobre as possibilidades da cooperação intergovernamental.

Eduardo José Grin (eduardo.grin@fgv.br) é Doutor em Administração Pública e Governo pela FGV São Paulo e professor da Escola de Administração de Empresas de São Paulo.

Fernando Luiz Abrucio (fernando.abrucio@fgv.br) é Doutor em Ciência Política pela USP e professor da Escola de Administração de Empresas de São Paulo.

\section{Referências}

Afonso, J. R. \& Araújo, E. A. (2000) A capacidade de gasto dos municípios brasileiros: arrecadação própria e receita disponível. Cadernos Adenauer, 4(s/n), pp. 35-57.

Agranoff, R. (2001) American Federalism and the Search for Models of Management. Public Administration Review, 61(6), pp. 671- 681. DOI: 10.1111/0033-3352.00138

Agranoff, R. (2007) Intergovernmental Policy Management: cooperative practices in federal systems. In: M. A. Pagano \& R. Leonardi (eds) The dynamics of federalism in national and supranational political systems. New York: Palgrave Macmillian, pp. 248-285. DOI: 10.1057/9780230625433 
Agranoff, R. \& McGuire, M. (2004) Another Look at Bargaining and Negotiating in Intergovernmental Management. Journal of Public Administration Research and Theory, 14(4), pp. 495-512. DOI: 10.1093/jopart/muh033

Agranoff, R. \& Radin, B. A. (2014) Deil Wright's Overlapping Model of Intergovernmental Relations: The Basis for Contemporary Intergovernmental Relationships. Publius: The Journal of Federalism, 45(1), pp. 139-159. DOI: 10.1093/publius/pju036

Biesbroek, R., Peters B. G. \& Tosun, J. (2018) Public Bureaucracy and Climate Change Adaptation. Review of Policy Research, 35(6), pp. 766-791. DOI: 10.1111/ropr.12316

Brendan, F. B. (2014). Understanding Intergovernmental Relations, Twenty-five Years Hence. State and Local Government Review, 46(1), pp. 63-76. DOI: 10.1177/0160323X13520461

Conlan, T. \& Posner, O. L. (2016) American Federalism in an Era of Partisan Polarization: The Intergovernmental Paradox of Obama's “New Nationalism". Publius: The Journal of Federalism Advance, 46(3), pp. 281-307. DOI: 10.1093/publius/pjw011

Derthick, M. (1972) New Towns in-Town. Washington, D. C.: The Urban Institute.

Downs, A. (1967) Inside Bureaucracy. Boston: Little, Brown and Company.

Elazar, D. (1987) Exploring Federalism. Toscallosa: University of Alabama Presss.

Elazar, D. (1994) Federalism and the way to peace. Ontario: Institute of Intergovernmental Relations.

Elazar, D. (1972) American Federalism: a view from the states. New York: Harper \& Row Publishers.

Grin, E. J. (2014) Trajetoria e avaliação dos programas federais brasileiros voltados a promover a eficie^ncia administrativa e fiscal dos municipios. Revista de Administração Pública, 48(2), pp. 459-480. DOI: 10.1590/0034-76121399

Grin, E. J. \& Abrucio, F. L. (2018a) Las capacidades estatales de los municipios brasileños en un contexto de descentralización de políticas. Reforma y Democracia, s/v(70), pp. 93-126.

Grin, E. J. \& Abrucio, F. L. (2018b) Quando nem todas as rotas de cooperação intergovernamental levam ao mesmo caminho: arranjos federativos no Brasil para promover capacidades estatais municipais. Revista do Serviço Público, 69(s/n), pp. 85-122. DOI: 10.21874/rsp.v69i0

Grin, E. J., Nascimento, A. B., Abrucio, F. A. \& Fernandes, A. S. A. (2018) Sobre desconexões e hiatos: uma análise de capacidades estatais e finanças públicas em municípios brasileiros. Cadernos de Gestão Pública, 23(76), pp. $312-336$. DOI: $10.12660 /$ cgpc.v23n76.75417

Grodzins, M. (1984) The American System: a new view of government in the United States. Chicago: Rand McNally \& Company.

Guarneri, L. S. (org) (2002) Modernização da gestão publica: uma avaliação de experiências inovadoras. Rio de Janeiro: BNDES.

Henriques, R. \& Reiff, L. O. (2010) O "S" do BNDES e a sustentabilidade do desenvolvimento. In: A. C. Além \& F. Giambiagi (orgs) O BNDES em um Brasil em transição. Rio de Janeiro: BNDES.

Howlett, M. \& Tosun, J. (2019) Policy styles: a new approach. In: M. Howlett \& J. Tosun (eds) Policy Styles and Policy-making: exploring the linkages. New York: Routledge, pp. 3-21.

Immergut, E. (1990) The rules of the game: The logic of health policy-making in France, Switzerland, and Sweden. Journal of Public Policy, 10(4), pp. 391-4I6. DOI: 10.1017/CBO9780511528125.004

Immergut, E. (1998) The theoretical Core of the New Institucionalism. Politics \& Society, 26(1), pp. 5-34. DOI: $10.1177 / 0032329298026001002$

Kim, J., McDonald, B. \& Lee, J. (2018) The Nexus of State and Local Capacity in Vertical Policy Diffusion. American Review of Public Administration, 48(2), pp. 188- 200. DOI: 10.1177/0275074016675966

Kane Jr., T. (1984) City Managers View Intergovernmental Relations. Publius - The Journal of Federalism, 14(3), p. 121-133. DOI: 10.1093/oxfordjournals.pubjof.a037490

Luna, J. P. \& Soifer, H. D. (2017) Capturing Sub-National Variation in State Capacity: A Survey-Based Approach. American Behavioral Scientist, 61(8), pp. 887-907. DOI: 10.1177/0002764217720964

McMenamin, I. (2006) Process and text: teaching students to review the literature. Political Science \& Politics, 39(1), pp. 133-135. DOI: 10.1017/S1049096506060306

Mahoney, J. (2003) Tentative Answers to Questions about Causal Mechanisms. In: American Political Science Association. Philadelphia.

Marenco, A. (2017) Burocracias profissionais ampliam capacidade estatal para implementar políticas? Governos, burocratas e legislação em municípios brasileiros. Dados, 60(4), pp. 1025-1058. DOI: 10.1590/001152582017141

Marenco, A., Blanco, M. T. S. \& Joner, W. (2017) Capacidade estatal, burocracia e tributação nos municípios brasileiros. Revista de Sociologia Política, 25(64), pp. 3-21 DOI: 10.1590/1678-987317256401

Newcomer, K. E. \& Triplet, T. (2006) Using surveys. In: J. S. Wholey., P. H. Harry \& K. E. Newcomer (eds) Handbook of practical program evaluation. San Francisco: Jossey-Bass, pp. 262-297. DOI: 10.1002/9781119171386

Peterson, P. E. (1995) The Price of Federalism. Washington, D.C.: The Brookings Institution.

Phillimore, J. (2013) Understanding Intergovernmental Relations: Key Features and Trends. Australian Journal of Public Administration, 72(3), pp. 228-238. DOI: 10.1111/1467-8500.12025

Pierson, P. (2004) Politics in Time: History, Institutions, and Social Analysis. Princeton: Princeton University Press.

Pierson, P. (1993) When the effect becomes cause: Policy feedback and political change. World Politics, 45(4), pp. 595-628. DOI: $10.2307 / 2950710$ 
Pressman, J. (1975) Federal Programs and City Politics. Berkeley: University of California Press. DOI: $10.1525 / 9780520315082$

Ragin, C. C. (1987) The Comparative Method: Moving beyond Qualitative and Quantitative Strategies. Jackson: University of California Press.

Savoia, A. \& Sen, K. (2015) Measurement, evolution, determinants, and consequences of State capacity: a review of recent research. Journal of Economic Surveys, 29(3), pp. 441-458. DOI: 10.1111/joes.12065

Skocpol, T. (2002) Bringing the state back in: strategies of analisys in current research. In: P. B. Evans, D., Ruesschemeyer, D. \& T. Skocpol (eds) Bringing the state back in. Cambridge: Cambridge University Press, pp. 3-41. DOI: 10.1017/CBO9780511628283

Souza, C. \& Blumm, M. (1999) Autonomia política local: uma revisão da literatura. Revista Brasileira de Informações Bibliográficas em Ciências Sociais - BIB, s/v(48), pp. 51-67.

Terman, J. N., Kassekert, A., Feiock, R. C. \& Yang, K. (2016) Walking in the Shadow of Pressman and Wildavsky: Expanding Fiscal Federalism and Goal Congruence Theories to Single-Shot Games. Review of Policy Research, 33(2), pp. 124-139. DOI: $10.1111 /$ ropr.12166

Veloso, J. F. A., Monasterios, L. M., Vieira, R. S. \& Miranda, R. B. (orgs) (2011) Gestão municipal no Brasil: um retrato das prefeituras. Brasília: Ipea.

Wright, D. S. (1988) Understanding Intergovernmental Relations. Pacific Grove: Brooks/Cole Publishing Company.

Wright, D. S. \& Stenberg, C. W. (2007) Federalism, Intergovernmental Relations, and Intergovernmental Management: The Origins, Emergence, and Maturity of Three Concepts across Two Centuries of Organizing Power by Area and Function. In: J. Rabin., W. Bartley \& G. J. Miller (eds) Handbook of Public Administration. London: New York: CRC Press, pp. 407-480.

\section{Outras fontes}

Banco Nacional de Desenvolvimento Econômico e Social. (2009) Guia de operações com mandatário. Rio de Janeiro: BNDES.

Banco Nacional de Desenvolvimento Econômico e Social. (2010) Apresentação da linha de Financiamento do BNDES para Modernização da Administração Tributária e de Gestão dos Setores Sociais Básicos - BNDES PMAT. Rio de Janeiro: BNDES.

Banco Nacional de Desenvolvimento Econômico e Social. (2013). Programa de Modernização da Administração Tributária e da Gestão dos Setores Sociais Básicos - BNDES PMAT. Rio de Janeiro: BNDES.

Banco Nacional de Desenvolvimento Econômico e Social. (2011) PMAT. Apresentação da linha de Financiamento do BNDES para Modernização da Administração Tributária e de Gestão dos Setores Sociais Básicos - BNDES PMAT e BNDES PMAT Automático. Rio de Janeiro: BNDES.

Secretaria do Tesouro Nacional. (2011) Operações de Crédito de Estados e Municípios. Manual para Instrução de Pleitos MIP. Brasília: STN.

\section{Entrevistas}

Eduardo Scalia e Diego Romero, Gerência Nacional de Programas e Políticas Públicas (CEF).

Eduardo Strantz, Coordenador de Estudos Técnicos da CNM.

Eduardo Tadeu Pereira, Presidente da ABM.

Gilberto Perre, Diretor Executivo da FNP.

Irapuan Braga e Jorge Henrique de Araújo Souza, Departamento de Gestão Pública do BNDES.

Rodrigo André Rêgo, Coordenador-Geral de Programas e Projetos de Cooperação (MF).

\section{Glossário de Siglas}

ABM - Associação Brasileira de Municípios

BB - Banco do Brasil

BNDES - Banco Nacional de Desenvolvimento Econômico e Social

CAUC - Serviço Auxiliar de Informações para Transferências Voluntárias

CEF - Caixa Econômica Federal

CMN - Conselho Monetário Nacional

CNM - Confederação Nacional de Municípios

CNPJ - Cadastro Nacional da Pessoa Jurídica

FGTS - Fundo de Garantia do Tempo de Serviço

FNP - Frente Nacional de Prefeitos

FPM - Fundo de Participação dos Municípios

IBGE - Instituto Brasileiro de Geografia e Estatística

ICMS - Imposto sobre Circulação de Mercadorias e Serviços 
IPTU - Imposto Predial e Territorial Urbano

ISS - Imposto Sobre Serviços

MIP - Manual de Instrução dos Pleitos

PMAT - Programa de Modernização das Administrações Tributárias

STN - Secretaria do Tesouro Nacional

The missing link of decentralization in Brazil: the promotion of municipal state capacities by the federal government

Keywords: state capacities; PMAT; federative dissonance; municipalities; intergovernmental cooperation.

ABSTRACT Introduction: The article addresses the promotion of municipal state capacities through the Tax Administration Modernization Program (PMAT), implemented by BNDES, between 1997 and 2014. It seeks to analyze how federal programs that promote municipal state capacities, implemented by sub-governments (federal public bureaucracies with reasonable autonomy of action to define their rules), can generate federative dissonance and reduce their possibility of access if they disregard the different municipal realities. Materials and Methods: were used quantitative techniques (descriptive statistics generated from the PMAT municipal adhesion reports and a Websurvey with the city halls) and qualitative techniques (interviews with federal managers - BNDES, Ministry of Finance and Caixa Econômica Federal - and political and technical leaderships of the National Confederation of Municipalities, Brazilian Association of Municipalities and National Front of Mayors. The theoretical argument is that dissonances between the federal agencies that provide programs and the municipalities as recipients produce low performance in terms of adhesion. Results: the research showed how games of federative cooperation can result in contrasting views between feds and locals. Empirically, this discussion was based on the implementation of the PMAT and how the explanatory mechanism of federative dissonance allows us to understand the relationship between "donor" and "recipient" in the midst of intergovernmental relations. The result of federative cooperation was the opposite of what its most benign view advocated as it encouraged more defensive actions by municipalities that weighed the costs and benefits of accessing the PMAT. Discussion: given the institutional design of the PMAT, considering the combination of the requirements for municipal entry and the fact that the applications are voluntary, the inducements favored the largest municipalities. Asymmetry of access was generated, which favored the most affluent cities. The federative dissonance between the BNDES and the municipalities is what explains the reality of the adhesions and the mismatch between the feds and the locals. With their format, rules of induction and disagreements over their operation, in federal terms, programs with these characteristics have little chance of being successful as a means of access for the vast majority of cities. The article contributes to the knowledge about the design of federal programs and their rules of access by subnational entities, especially those to promote municipal state capacities. Another contribution is that the way in which feds design and implement programs influences the type of municipal membership. The action of subgovernments can generate views that do not coincide between federal managers and the municipal reality. This is another contribution to the literature on federalism and state capacities of local governments.

This is an Open Access article distributed under the terms of the Creative Commons Attribution Non-Commercial License which permits unrestricted non-commercial use, distribution, and reproduction in any medium provided the original work is properly cited. 